\title{
A Comparative Study of Access to Web-Enabled Services in Botswana and the UK: Issues, Obstacles and Solutions
}

\author{
Conference discussion group paper \\ Moses Mmileng Moreri, Maubrey Russ Pitso, and Alan Strickley \\ e-Gov. Programme Botswana, Office of the President, Botswana, and CRIA Technologies UK
}

\begin{abstract}
This paper looks at the issue of access to internet based services in Botswana and the UK. It provides an overview of current infrastructure and demographics in each country, the particular issues and obstacles that each faces and considers the initiatives currently being pursued. It concludes that although the two countries may be very different many of the problems they face with regards to web access are similar.
\end{abstract}

Keywords: UK, Botswana, web, access, internet, channels, e-government.

\section{Introduction to the Two Countries}

Botswana is a country with an area of 581,730 square kilometres and a population of $1,990,876$ whilst the UK has an area of 243,610 square kilometres and a population of $62,041,708$.

Whilst on the face of it they are two very different countries in terms of size and population, many of the challenges surrounding access to ICT services and participation in web-channel engagement are similar.

This paper looks at the issues, obstacles and solutions to engaging the whole of the populations of these two countries in using new technology for education, training, business, employment and social inclusion.

\section{Botswana}

\subsection{Introduction}

The Government of Botswana has adopted Information and Communication Technology (ICT) as one of the major tools to propel its economic growth and development. In that regard, the National ICT Policy dubbed 'Maitlamo' was adopted in 2007 with the main goals being to provide an enabling environment to assist in the implementation of key strategies essential for achieving the country's national development targets within the scope of ICT. The Maitlamo policy also addresses the subject of community access to ICT, which is critical to promote citizen access to Government services in the country. The implementation of the policy during the current planning period is expected to help the public sector to deliver quality services 
by allowing citizens to access government information and services at any time of the day, and without having to travel long distances, or to wait in long queues to receive services. The following sections address key issues, obstacles and solutions to the provision of web-enabled services, or e-Government, in Botswana.

\subsection{Issues}

While Botswana is still categorized as a developing country, there exists great potential for the country to grow through ICT. Generally, an ICT framework has been developed to support the provision of web-enabled services, though there are still issues of poor connectivity and low internet penetration in the country. The Maitlamo policy aims to propel Botswana to become "...a globally competitive, knowledge and information society where lasting improvement in social, economic and cultural development is achieved through effective use of ICT" (Botswana Government, 2007). The Government intends to achieve this through a multi-pronged strategy that includes seven robust objectives dealing with issues of connectivity, access and enhanced service delivery.

According to the e-Readiness Report compiled in 2004, Botswana is one of the few developing countries which have a good coverage of highly sophisticated fibre network coverage. This is further expected to be strengthened through connections to the West African Cable System (WACS) and the East Africa Submarine Cable System (EASSy) that will be providing high performing broadband networks between Botswana and the rest of the world. However, current statistics show that access to ADSL/Broadband connection is only around $1-2 \%$, computer home ownership is at $3 \%$ and internet penetration at a low of $6 \%$. This therefore implies that usage of the internet for web-enabled services is still very low. Interestingly, Botswana is ranked number three (3) in Africa and one-hundred and seventeen (117) in the world which could be attributed to mobile telephony. Further information reveals that the country may well overtake South Africa and Nigeria in cellular phone penetration which is above $85 \%$ currently. This provides ample opportunity for internet penetration through what some countries have labelled 'm-Gov' or mobile Government. Though accessibility is on the increase, the country has been slipping consistently in terms of global connectivity ranking, which should be a wake-up call for the country to do more in order to realize benefits from web-enabled services.

Several initiatives are currently being pursued to promote the use of the internet which is the gateway to web services. Among the most prominent are:

Thuto Net: involves exposing young children and adults to the internet both at school and community levels. Among some of the projects under the programme are the refurbishment of computers from Government offices for re-allocation to primary schools, and broadband connectivity to all schools. Significant progress has been made so far with almost all secondary schools and a substantial number of primary schools connected.

e-Health: aims at providing better healthcare to citizens through the transformation of health care systems, enabling excellent patient care, improving online access to health services and information and providing a national health surveillance network to systematically manage emerging issues in health care. 
e-Business: online transactions between government and business following models adopted in the private sector where procurement and payments for goods and services can be made online

e-Legislation: an initiative to remove all legal impediments to the implementation of e-Government such as the introduction and recognition of electronic signatures.

As the biggest employer in Botswana, Government has also introduced an initiative to promote computer ownership among its employees by allowing workers to purchase computers at subsidized rates. The initiative, called " i-Partnership, Computer for Me", is currently being reviewed to make it more responsive to current challenges.

On the public service front, citizens have for a long time been decrying lack of efficient and effective service in Government. It is a fact that customer expectations are always on the rise. In 2005, the Public Service Customer satisfaction survey recorded a rating of $25 \%$, and in 2008/09, this rating increased by only 2 percentile points to $27 \%$. One of the most effective ways to match customers' demands is the use of ICT in business, and hence the Government's decision to adopt an eGovernment strategy. In essence, e-Government strategy has the transformational ability of 'taking Government to the people', and offers an opportunity for reduced Government red-tape and increased delivery. Our current national development plan sets high goals and a target of $75 \%$ of customer satisfaction rating for the year 2016 . To a large extent, the pace at which the country excels at implementing the National ICT Policy, or Maitlamo, will determine the success and service delivery outcomes for 2016.

\subsection{Obstacles}

As a developing country, Botswana has many factors hampering the use of ICT for efficiency and effectiveness gains. Despite the many efforts that the Government is pursuing, there are still challenges relating to some of the following issues:

Access to ICT infrastructure, internet penetration and telephone coverage

While the country is surrounded by fibre, the network only goes to major villages and towns, leaving out the majority of citizens who stay in remote areas. The general internet penetration is also very low. The issue is aggravated by the fact that Botswana as a landlocked country depends on South Africa for its bandwidth, and the supply is dependent on the needs of the South Africans. Whenever they require more bandwidth, Botswana will get less. To address these, a rural connectivity programme was launched to connect 197 villages to the telecommunications grid, and hopefully this will extend ICT reach to all parts of Botswana. Botswana has also taken part in the procurement of international under-sea cable connectivity (EASSY and WACS) which should remedy the issue of bandwidth shortage by 2012 .

Unavailability of electricity in some of the localities

Of the 800 public primary schools in Botswana, only 500 schools have got electricity. This means that about 300 schools might not benefit from the computer refurbishment project due to this issue. The country is also very large, with a low population density. The connection of electricity to all villages is therefore financially and geographically challenging.

Shortage of trained personnel and limited ICT skills 
Competent personnel are required to teach and support ICT related training in schools, especially in rural areas. Also, our largely rural population still lack ICT skills which would enable them to access Government online services.

Financial limitations

As a developing country with priorities still set largely on provisions of basic goods and services such as education, healthcare and infrastructure, the country faces financial constraints which would otherwise help the Government to move at a much faster pace. As a developing nation and highly dependent on mineral exportation, Botswana was not sparred of the recent global economic crisis. This however, may not be used as an excuse for provision of e-Services even though developing countries by default have this challenge of unavailability of funds.

Slow or inefficient project implementation

Generally, Botswana has very good and robust development plans in place. However, implementation has been found to be wanting in most cases, with the resultant slow delivery of projects and associated cost overruns.

High cost of ICT services

Botswana has got a high penetration of mobile phones, but the challenge is the cost of calling and procuring the smart phones which can allow access to both internet and other media. This is mainly because Botswana's tariffs are tightly dependant on the South African ones.

Mindset and Attitudinal issues

A strategy to take the nation through a transformational process to use and adapt to ICT needs to be developed.

Lack of e-Legislation

Though the country plans to enact e-Laws to support its e-Government framework, this component is still lagging behind thus inhibiting the use and recognition of electronic signatures.

Poor internet connectivity and low bandwidth

Ministries attempting to deliver web-enabled services experience low bandwidth which results in prolonged downtime of their systems. As a result, citizens find it difficult to access available online services.

\subsection{Solutions}

Clearly, there are many issues affecting the use of ICT and delivery of web-enabled services in Botswana. However, much has been done and continues to be done in order to address bottlenecks so far experienced. Among the many solutions put in place to address these problems are:

E-Government Programme: to leverage on ICT for delivering service to citizens. The e-Government Programme is structured in three (3) main streams among them an e-Legislation component specifically to address all legal issues in e-Gov.

Connection of the country to undersea cable systems to boost internet bandwidth and connectivity.

Use of cellphones (m-Gov) to deliver some services as cellphone penetration is very high in the country.

A rural electrification programme to connect all areas with a population of more than two-hundred and fifty inhabitants to the national power grid. Opportunities for 
the use of solar are also available as the country is blessed with sunshine throughout the year.

Implementation of a national human resource development strategy, to include ICT skills for Teachers and the rest of the citizens.

Establishment of Kitsong Centres, Sesigo and such other initiatives to provide convenient centres that provide local residents access to computers and other ICT equipment in Public Libraries and Post Offices which can be found in almost all localities of the country.

Establishment of a National Strategy Office with a robust M\&E system to manage project implementation.

Partnerships with development partners are also promoted in order to share costs and results of e-Government.

\subsection{Conclusions}

It is clear from the picture presented above that while opportunities exist for the promotion of web-enabled services in Botswana, there are still some challenges. However, it is important that learning and experiences from countries that have advanced in this sphere can be used to deliver effective service to citizens. The Government of Botswana also has good plans in place which can benefit even some of the advanced economies such as that of the United Kingdom.

\section{United Kingdom}

\subsection{Issues}

Most schools and colleges within the UK have wide access to the internet and use elearning across the curriculum. As a result access to web services within education are high. However access at home may not be available to all learners.

In this respect it has been shown (Harris \& Goodall, 2007, Ofsted, 2007 and DfES, 2007) that home access can enhance learner achievement, increase motivation and improve parental engagement, which can in turn raise children's attainment. Recent evidence has also suggested that having home access to a computer could help learners achieve a two grade improvement in one subject at GCSE. Effectively, a pupil that would have got a D, could, through the effective home use of technology, now get a B at GCSE. (Becta, 2010) Longer term, Price Waterhouse Coopers [Race Online, 2010] estimate that increases in educational attainment could result in lifetime earnings increases of $£ 10.5$ billion.

Parental engagement in the learning and education of their children can improve their educational outcomes. Research shows that children achieve more highly when their parents talk to them about their experience of school and learning. However, a recent report (Becta 2010b) showed that $82 \%$ of parents felt 'left 'in the dark' when it comes to their child's schooling. The introduction of online reporting means that parents are able to have secure online access to information on their child's progress, achievement, attendance and behaviour. It enables parents to get closer to and support 
their child's learning, enabling them to work as equal partners in improving learning outcomes for their child. This can be achieved through the effective use of established management information systems, without increasing the workload of teaching staff.

With additional access to personalised learning which includes assessment, teaching, curriculum and school strategies, designed to ensure that the talents of every individual can be fully realised, standards can be raised for all by setting high expectations based on a sound knowledge and understanding of every child (Milliband. 2010). The use of e-learning packages through a Virtual Learning Environment (VLE) can help to assist in this objective.

As a result the position for those in education is good. In addition (Race Online, 2010) $58 \%$ of UK adults buy goods and services online spending an estimated $£ 4.4$ billion in April 2010, 87\% of UK internet users make travel plans over the internet and 25 million have facebook accounts. Of the 40 million internet users, there are about 30 million using it every day.

Therefore there are over 10 million people in the UK who have never been online for any purposes representing about $20 \%$ of the population. Yet there are some compelling advantages to using the internet estimated at over $£ 22$ billion in terms of consumer, educational, employment and government efficiency (Race Online, 2010).

Indeed more than $90 \%$ of new jobs require basic internet skills with many new jobs being offered initially on the internet or in some cases only online. This further illustrates the statistic that 270,000 people on job seekers allowances have not used the internet (Race Online, 2010).

Therefore there is a compelling case for introducing those in the $20 \%$ of non-users to use the internet and also to increase presence, particularly for public services, into web-based access channels.

\subsection{Obstacles}

The UK has a good broadband infrastructure (see Figure 1) and availability is clearly not an obstacle in accessing web services.

Reasons for the lack of usage range from lack of skills, access and motivation. Non-usage studies suggest that the highest concentrations of the working age population are in socially derived areas whilst the highest concentration of older people (65 and over) with non-usage is concentrated in rural and coastal areas.

Older people often perceive that the internet is not suited to them. However this may not the case with home shopping, medical advice and cheaper prices being available through this access channel.

An additional obstacle is the administrative structure of the UK, with LAs having control over the content and structure of local services, meaning that there is a nonuniform structure to the provision of web-based council services.

\subsection{Solutions}

The UK has a widespread cabled broadband infrastructure with 18.3 million households in the UK (70 per cent) having Internet access in 2009. 


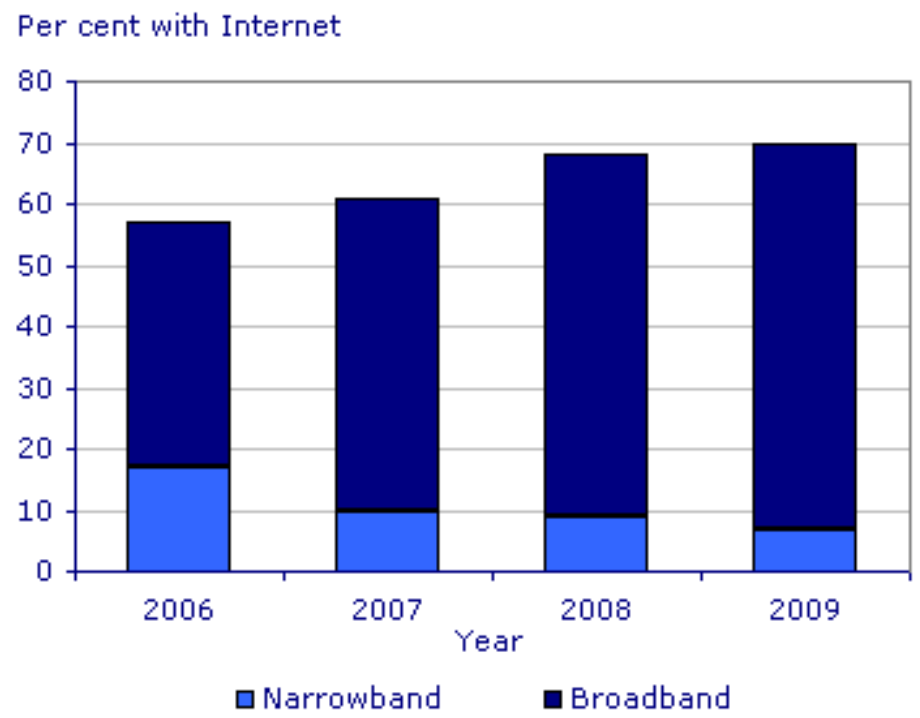

Fig. 1. Households with access to the Internet, UK (OFNS, 2009)

The use of mobile internet access is also widespread with $2 \mathrm{G}$ covering $99 \%$ of the UK population and $3 \mathrm{G}$ around $90 \%$. However isolated areas will not be covered (BBG, 2010).

Clearly the issues are not merely about availability of service. However the issues of hardware, education and awareness are key.

There are a number of initiatives that are attempting to increase web usage amongst the population. These are:

e-Government: This programme ran until 2006 and was tasked with ensuring that all council services were available electronically by the end of the programme. Some LAs got round this by creating downloadable forms or documents. However the eAdmissions project was a major success achieving a transactional online admissions form in all 150 LAs in England.

Putting the Frontline First: Smarter Government (HMSO ,2009) was an initiative by the previous administration to increase online take up with an input of $£ 30$ million and included targets of $80 \%$ for tax and admissions online usage.

Race Online 2012 (2010): This is an initiative from the current administration that aims to get 10 million more people online by 2012 and $100 \%$ take up of a number of online services. There appears to be little funding for this initiative though.

Connect Digitally: This programme has set targets for $50 \%$ take-up of online admissions, 60\% Free School Meals and 75\% linked services across all LAs in England by 2011. Now in its second year the programme is making good progress through partnership working with local authorities in England.

Home Access (Becta 2010a): This initiative is a government drive that helps lowincome families who currently lack access to a computer and/or internet to get online at home to support learning. It involves a grant for a computer, internet access and 
support for 270,000 households. Whilst the programme is primarily aimed at school age pupils, it is hoped that usage will extend within the household to parents.

Reporting to Parents: The statutory provision of real-time reporting to parents through web-enabled channels will not only help pupil achievement but will encourage parental involvement in the use of the internet.

\section{Conclusions}

Clearly the initiatives are there and it is to be seen how effectively they will be in extending the use of web-based services in the UK in a time of financial restraint.

\subsection{General Conclusions}

Both countries are embarking on initiatives to enable access to government information and services in order to facilitate 24/7 availability, convenience and efficiency. To this end they are both striving towards being globally competitive through the use of ICT. Both see the importance of universal access to web-based services and have initiated programmes to enable access through educational establishments, communities and business including making e-communication more available through legislation and free/assisted purchase of personal computers for home use.

Botswana clearly has a less mature infrastructure both in terms of broadband and in some cases more basic utilities such as electricity. As a developing country ICT competencies and financial limitations are obstacles. However the problems surrounding ICT projects and the challenges of attitudes and mindsets are a common theme.

It is clear that both countries have progressive policies regarding the inclusion of all of their populations into the use of the internet and whilst there may be some differences, there is much that the two countries can learn from each other.

\section{References}

BBG, A guide to national mobile broadband coverage (2010),

http: / /www.broadbandgenie.co.uk/mobilebroadband/help/

guide-to-national-mobile-broadband-coverage

(accessed August 10, 2010)

Becta, Home Access (2010a),

http://localauthorities.becta.org.uk/index.php?section= eo\&catcode=la_hom_01\&rid=15851 (accessed August 10, 2010)

Becta, $82 \%$ of parents left 'in the dark' when it comes to their child's schooling (2010b), http: / / news . becta.org.uk/display. cfm?resID=39820

(accessed August 10, 2010)

Botswana Government, Government Paper No. 3 of 2007: National Information and Communications Technology Policy - Maitlamo. Gaborone: Ministry of Communications, Science \& Technology (2007) 
Botswana Government, National Development 10 - 2009/2016. Gaborone: Government Printer (2010)

Botswana Government, Botswana's National e-Government Strategy - 2011/2016. Working Paper for the e-Government Project Office. Gaborone. Ministry of Transport \& Communications (2010)

DfES, Every Parent Matters. DfES: Nottingham (2007)

Harris, A., Goodall, J.: Engaging parents in raising achievement: Do parents know they matter. University of Warwick, Coventry (2007)

Large, A., Tedd, L.A., Hartley, R.J.: Information Seeking in the Online Age. KG Saur, Munchen (2001)

Little, D., Bose, A.: National ICT e-readiness Assessment Report: Infrastructure (2004), http: / /www.maitlamo.gov.bw/docs/e-readiness / volume-1/

Milliband, D.: What does personalised learning mean to you? (2010), http: / /www. teachernet.gov.uk/teachers/issue31/primary/features / Whatdoespersonalisedlearningmeantoyou_Primary/ (accessed August 10, 2010)

OFNS. Internet Access 70\% of households had access in 2009 (2009), http: / / www.statistics.gov.uk/cci/nugget.asp?id=8 (accessed August 10, 2010)

Ofsted, Parents, carers and schools (2007), http: / /www. ofsted.gov.uk/Ofsted-home/Publications-andresearch/Education/Leadership/Management/Parents-carers-andschools / language/eng-GB (accessed October 08, 2008)

HMSO, Putting the frontline first: smarter government. TSO: Norwich (2009)

Race Online, Manifesto for a networked nation. Host: London (2012)

Teaching Expertise, Online reporting to parents (2010), http: / /www. teachingexpertise.com/blog/ online-reporting-parents-3947 (accessed August 10, 2010)

UN DESA, E-Government survey 2010 (2010), http: / / www. un.org/eng/development/desa/ 